\title{
Systematic review and meta-analysis of a variety of chemicals to treat migraine in the neurology department
}

\author{
Yi Zhang ${ }^{1}$, Yushaung Deng ${ }^{2}$, Shanshan Zhang ${ }^{1}$, Xin Du ${ }^{1}$, Yifei Ji ${ }^{1}$ \\ ${ }^{1}$ Department of Neurology, Nanchong Central Hospital/The Second Clinical Medical College of North Sichuan Medical College, Nanchong, \\ China; ${ }^{2}$ Department of Neurology, Chengdu Second People's Hospital, Chengdu, China \\ Contributions: (I) Conception and design: Y Zhang, Y Deng; (II) Administrative support: S Zhang; (III) Provision of study materials or patients: Y \\ Zhang, Y Deng, X Du, Y Ji; (IV) Collection and assembly of data: All authors; (V) Data analysis and interpretation: Y Zhang, S Zhang, X Du, Y Ji; (VI) \\ Manuscript writing: All authors; (VII) Final approval of manuscript: All authors. \\ Correspondence to: Yi Zhang. Department of Neurology, Nanchong Central Hospital/The Second Clinical Medical College of North Sichuan Medical \\ College, No. 97, Renmin South Road, Shunqing District, Nanchong, China. Email: wing_z_y3@126.com.
}

Backgrounda Migraine refers to a group of recurrent, chronic, neurological, and vascular diseases. Longterm recurrent migraine not only affects personal life and work, but also results in a huge economic burden on the family and society. Timely and accurate diagnosis of migraine and early and standardized treatment can effectively control migraine attacks. The treatment of migraine is to quickly stop the attack, relieve the associated symptoms, prevent recurrence, and restore normal life function as soon as possible.

Methods: Literature retrieval was performed in the PubMed, Embase, and OVID-Medline English databases, and the retrieval period was from the establishment of the database to April 2021. Keywords such as migraine, chemical drugs, and therapeutic effect were used.

Results: A total of 13 studies involving 1,921 migraine patients were included. The results showed that there was a significant difference in incidence of adverse events in patients after treatment with chemical drugs and placebo [risk difference $(\mathrm{RD})=0.11 ; 95 \%$ confidence interval $(\mathrm{CI}): 0.03$ to $0.20 ; \mathrm{Z}=2.70 ; \mathrm{P}=0.007$ ] and the frequency of headaches [mean difference $(\mathrm{MD})=-1.31 ; 95 \% \mathrm{CI}:-1.89$ to $-0.73 ; \mathrm{Z}=4.40 ; \mathrm{P}<0.0001]$. The incidence of adverse events after topiramate treatment [odds ratio $(\mathrm{OR})=3.63 ; 95 \% \mathrm{CI}$ : 1.65 to 7.97 ; $\mathrm{Z}=3.21 ; \mathrm{P}=0.001]$ and the frequency of headache $[\mathrm{MD}=-1.31 ; 95 \% \mathrm{CI}:-1.87$ to $-0.75 ; \mathrm{Z}=4.59 ; \mathrm{P}<0.00001]$ was significantly different from the placebo group; The frequency of headache after sodium valproate treatment $[\mathrm{MD}=-0.92 ; 95 \% \mathrm{CI}:-1.80$ to $-0.04 ; \mathrm{Z}=2.05 ; \mathrm{P}=0.04]$ was also significantly different from the placebo group. However, there was no significant difference in the incidence of adverse events and the frequency of headaches after flunarizine and placebo treatment.

Discussion: A total of 13 articles were included to evaluate the efficacy and tolerability of chemotherapeutic treatments for migraine. This study found that sodium valproate and propranolol were well tolerated for the prevention and treatment of migraine. The clinical manifestations were mainly unilateral temporal pulsing headache, some patients were accompanied by visual aura, fatigue, emotional and other triggers, and nearly half of the patients had a family history.

Keywords: Migraine; a variety of chemicals; placebo; meta-analysis

Submitted Nov 08, 2021. Accepted for publication Jan 07, 2022.

doi: 10.21037/apm-21-3719

View this article at: https://dx.doi.org/10.21037/apm-21-3719 


\section{Introduction}

Migraine refers to a group of recurrent, chronic, neurological, and vascular diseases. In China, the incidence of migraine is as high as $9.3 \%$ (1). For the majority of patients with migraine, onset usually occurs in childhood and adolescence, and the peak occurs in middle-aged and young adults, most of which are females (2). Chronic and recurrent migraines not only affect personal life, but also result in a huge economic burden on families and society $(3,4)$. Migraine attacks cause physical discomfort, which can also lead to white matter lesions, cognitive decline, and asymptomatic posterior circulation cerebral infarction $(5,6)$. In addition, epidemiology has shown that migraine is associated with multiple diseases, such as anxiety and depression $(7,8)$, among which up to $18.8-42 \%$ of migraine patients have depression (9). Therefore, the clinical diagnosis and treatment of migraine warrants further study.

At present, the etiology of migraine is not clear. The following factors may be related, which can be summarized as internal and external causes (10). Internal causes include genetic susceptibility, where the risk of migraine in relatives of migraine patients is two to five times higher than that in the general population. Mutations in genes such as $C A C N A 1 A, S C N 1 A$, and $A T P 1 A 2$ can lead to familial, hemiplegic migraine. In addition, the onset of migraine is also concerned with endocrine and metabolic factors. External causes include certain foods (cheese, preserved meat, etc.) and drugs (birth control pills, vasodilators, nitroglycerin, etc.) $(11,12)$. Migraines typically involve recurrent attacks, most of which are manifested as moderate to severe frontotemporal pain, usually unilateral and pulsing, lasting for several hours, often accompanied by autonomic nerve dysfunction such as nausea, vomiting, photophobia, and fear of sound. Some typical migraine patients with aura may have visual, sensory, and motor impairments before the attack (13), among which the most common is visual aura, which is manifested as binocular blurred vision, visual deformation, flash, bright spot line, or dark spot. The aura does not last more than an hour. At present, the pathogenesis of migraine mainly includes increased neuronal excitability, cortical spreading depression (CSD) trigger aura, abnormal function of trigeminal nervous system activation and central pain-regulating system leads to migraine attack, and progressive damage of midbrain periaqueductal cortex (PAG) leading to chronic migraine (14). In recent years, positron emission computed tomography (PET), voxel-based morphometry (VBM), diffusion tensor imaging (DTI), blood oxygenation level dependent functional magnetic resonance imaging (BOLDfMRI), and magnetic resonance spectrum imaging (MRS) have gradually been used in the study of migraine. New findings on brain morphology, metabolism, and function during and between migraines are described from various perspectives (15). It is generally believed that migraine attacks are associated with dilation of blood vessels in the brain and meninges. Migraine patients suffer from local vasospasm, reduced blood flow, and dilation of veins. It has been pointed out that during migraine attacks, cortical activation associated with pain processing mainly includes anterior and posterior cingulate gyrus, anterior frontal lobe, cerebellum, insula, and temporal lobe (16). The temporal pole activation is more obvious during the migraine attack than during the interictal phase during the heat pain stimulation. Compared with normal controls, migraine patients have more functional connections between the temporal pole and multiple brain regions, suggesting that hyperexcitability and abnormal functional connections of the temporal pole may be involved in the specific clinical manifestations of migraine (17). Chronic migraine is often associated with acute overuse of anti-migraine drugs. There have been studies of fluorodeoxyglucose (FDG)PET scans in patients with headache overdoses of antiinflammatory painkillers. Hypometabolism was found in bilateral thalamus, orbitofrontal cortex, anterior cingulate gyrus, insula/ventral striatum, and right inferior parietal lobe, while hypermetabolism was found in cerebellum vermis. Blood flow increased in cerebellum and volume of gray matter decreased in orbitofrontal cortex during attack. However, functional connectivity was enhanced in the anterior dorsal cingulate gyrus, and glucose metabolism abnormalities in these areas associated with pain processing basically returned to normal 3 weeks after drug withdrawal, but metabolic activity in the orbitofrontal cortex was further reduced (18).

For the onset phase, the acute phase is used primarily, where the main expected effects are rapid and continuous pain relief, improvement of concomitant symptoms, and restoration of the patient's normal life (19). Acute phase treatment drugs are divided into specific and non-specific types. The drugs commonly used during the onset include non-steroidal anti-inflammatory drugs (NSAIDs), ergot alkaloids, triptans, antiemetic, hypnotic, and adenosine receptor antagonist. By inhibiting cyclooxygenase, NSAIDs affect arachidonic acid metabolism and ultimately hinder prostaglandin synthesis, thus playing anti-inflammatory, analgesic, and antipyretic roles (20). Ergot drugs induce 
intracranial vasoconstriction, improve cerebral blood flow, and relieve headache symptoms by activating serotonin $1 \mathrm{~A}$ receptors (21). Antiemetics are usually used in patients with acute migraines with severe gastrointestinal symptoms. Sleep aids may be considered in migraine patients with associated disorders (22). For migraine patients, prophylactic treatment aims to reduce attacks, relieve pain, and increase the drug efficacy of acute treatment $(23,24)$. Prophylactic treatment drugs include calcium channel blocker, beta-receptor-blocking agent (3-blocker), anticonvulsant, calcitonin gene-related peptide (CGRP) receptor blocker, and petasitenine. Calcium antagonist can relieve headache by blocking calcium influx and relieving vasospasm. Receptor blockers are suitable for patients with angina pectoris, hypertension, and essential tremor. Anticonvulsants may prevent migraine attacks by stabilizing ion channels, blocking glutamate-mediated neurotransmission, and reducing neuronal excitation (25). CGRP is the strongest vasodilator. Petasitenine is Class A evidence drug in the 2012 American Academy of Neuroscience (AAN) Guidelines for Migraine Prevention (26). Migraine patients are closely related to sleep, emotional disorders, and mood disorders. The number of migraine patients with depression is up to $50 \%$, so antidepressants can be considered for treatment of migraine patients with depression (27). Topiramate and sodium valproate are antiepileptic drugs supported by extensive research. Although antiepileptic drugs have a good effect on the prevention of migraine, attention should be paid to the occurrence of adverse reactions, and regular blood routine, liver function, amylase, and other tests, as well as followup should be performed (28). Common adverse reactions to topiramate include paresthesia, weight loss, and lethargy. Long-term administration of sodium valproate and divalproex can lead to weight gain, pancreatitis, liver failure, and other adverse reactions (29). In the prevention of migraine, beta-blockers are widely used and have a clear effect, with an effective rate of up to $80 \%$, among which propranolol and metoprolol are the most welldocumented. In a previous randomized controlled trial (RCT), several researchers concluded that both drugs have a consistent and positive efficacy in preventing migraine (30). When using beta-blockers, it should be noted that patients with mood disorders have a greater chance of becoming depressed and even suicidal due to rare the side effects of depression (31). In modern society, with the accelerated pace of life and the aggravation of work pressures, migraine patients exhibit a significantly increased risk of anxiety and depression (32). Calcium antagonists have few adverse reactions, mainly including nausea, vomiting, dizziness, insomnia, etc. Antihypertensive drugs are especially suitable for migraine patients with angiotensin-converting enzyme inhibitor (ACEI) or angiotensin II receptor blocker (ARB) indications (33). After long-term treatment, candesartan tends to cause dizziness, fatigue, muscle and skeletal symptoms, and other adverse reactions. Lisinopril is prone to cough, dizziness, and fainting (34).

The efficacy of chemotherapeutic drugs in the treatment of migraine remains uncertain. Therefore, this paper will study the treatment of migraine with various chemotherapeutic drugs to provide an important theoretical basis and support for the subsequent clinical treatment of migraine. We present the following article in accordance with the PRISMA reporting checklist (available at https://apm. amegroups.com/article/view/10.21037/apm-21-3719/rc).

\section{Methods}

\section{Literature search strategy}

A comprehensive and systematic literature study was conducted based on the Cochrane Handbook of Systematic Reviews of Interventions, and meta-analyses were recorded according to the PRISMA. We searched PubMed, Embase, Ovid, PubMed, Medline, Springer, Web of Science, scientific conferences, and established articles. All the studies included patients treated for migraine. We used keywords and medical titles in specific searches that included the following: "chemodrugs", "topiramate", "propranolol", "metoprolol", and "migraine". The included articles were related to the treatment of migraine. The incidence rate was also included in the study as an indirect method to adjust the scope, course, and region of the disease.

\section{Literature inclusion and exclusion criteria}

The inclusion criteria were as follows: (I) study type: double-blind RCT, in which the class A recommended drugs (topiramate, sodium valproate, propranolol, metoprolol, flunarizine) in the Chinese Migraine Guidelines for the prevention and treatment were used in the experimental group alone, and a placebo was used in the control group (the dosage forms of the two experimental groups were oral drugs); (II) studies involving human subjects who met the diagnostic criteria for migraine set by the International Headache Society (IHS) or met the diagnostic criteria for 
migraine recognized internationally by researchers at the time of the study, and were at least 12 years old; and (III) the experimental data were not missing, the sample size was exact, and the intergroup data of the study object was complete.

Articles were excluded from the meta-analysis if they met any of the following exclusion criteria: (I) duplicate publications (excluding the same clinical trial due to different evaluation indicators of repeatedly published literature; first published data were extracted and included in the study); (II) literature that is inconsistent with the evaluation indexes of this study or does not provide valid data; (III) low-quality studies; and (IV) repeated or reprinted articles.

\section{Literature screening}

The two researchers first screened the titles and abstracts independently according to the inclusion criteria, and then extracted the data and evaluated the quality. When the evaluation results were inconsistent, the two researchers consulted with other researchers to resolve the discrepancy according to the original data of the articles. When the titles and abstracts met the inclusion criteria, the full text was retrieved for data extraction. Note Express 2.0 (Beijing Aegean Software Company, Beijing, China) was used for literature management and duplicate literature was deleted. The inclusion of studies was crosschecked according to the inclusion and exclusion criteria mentioned above, and relevant literature was retraced.

\section{Data extraction}

The two researchers independently extracted the relevant information from all eligible studies using a predefined data extraction table, including the author, year of publication, sample size, age, country, gender, degree of disease, and course of disease. Diagnostic criteria for ulcerative colitis (UC) and colorectal cancer (CRC) were extracted. For missing data, the researchers tried to contact the original authors of the literature via e-mail. For data that was unavailable, the Cochrane evaluation manual was used for relevant transformation, such as calculation of the standard deviation of continuous data.

\section{Quality assessment}

In order to improve the quality of the reviewed literature, quality was assessed in accordance with the "risk of bias assessment" recommended in version 5.3 of the Cochrane system review manual. The evaluation included the following seven items: (I) which random method was used; (II) whether allocate concealment was adopted; (III) implementation of a blinding method between patients and researchers; (IV) evaluation of the blinding method effect; (V) review information such as the generation, allocation hiding, and blinding of random sequences in the literature. A score of 1-3 in the four dimensions of tracking/exit was low quality, while a score of 4-7 was high quality.

\section{Data analysis}

The forest plot also clearly shows the results of individual studies, combining those studies with corresponding confidence intervals (CIs). If there was no overlap between the CIs of the individual studies, this indicated statistical inhomogeneity between the studies. Further subgroup analysis was required to combine stochastic and fixed models with acceptable inhomogeneity. Subgroups were divided according to different designs, and then the impact size of each subgroup could be ignored. The inhomogeneity between studies could not be ignored when different properties were investigated, and different properties could not be dealt with in order to deal with the inhomogeneity. The corresponding statistical model was selected for data analysis.

\section{Sensitivity analysis}

Sensitivity analysis of the research results was performed by investigating whether individual studies affected the overall results of the portfolio. Each included study was removed sequentially. Combined with the results of the remaining studies, the combined results of each study were compared with the individual results to confirm whether the results were the same. We believe that it will have an impact on the comprehensive study under the following two circumstances. Firstly, if a study is deleted, the presumption of the size of the combined effect is $95 \%$ of the size of the combined effect. When a study is deleted, the results yield significantly different results. If one study affects the overall results with little difference, this indicates the sensitivity of the combined results and the results obtained are not stable. On the contrary, the results showed that the sensitivity was stable and the conclusions were correct.

\section{Statistical analysis}

STATA11.0 software (StataCorp, USA), Cochrane 
Identification of studies via databases and registers

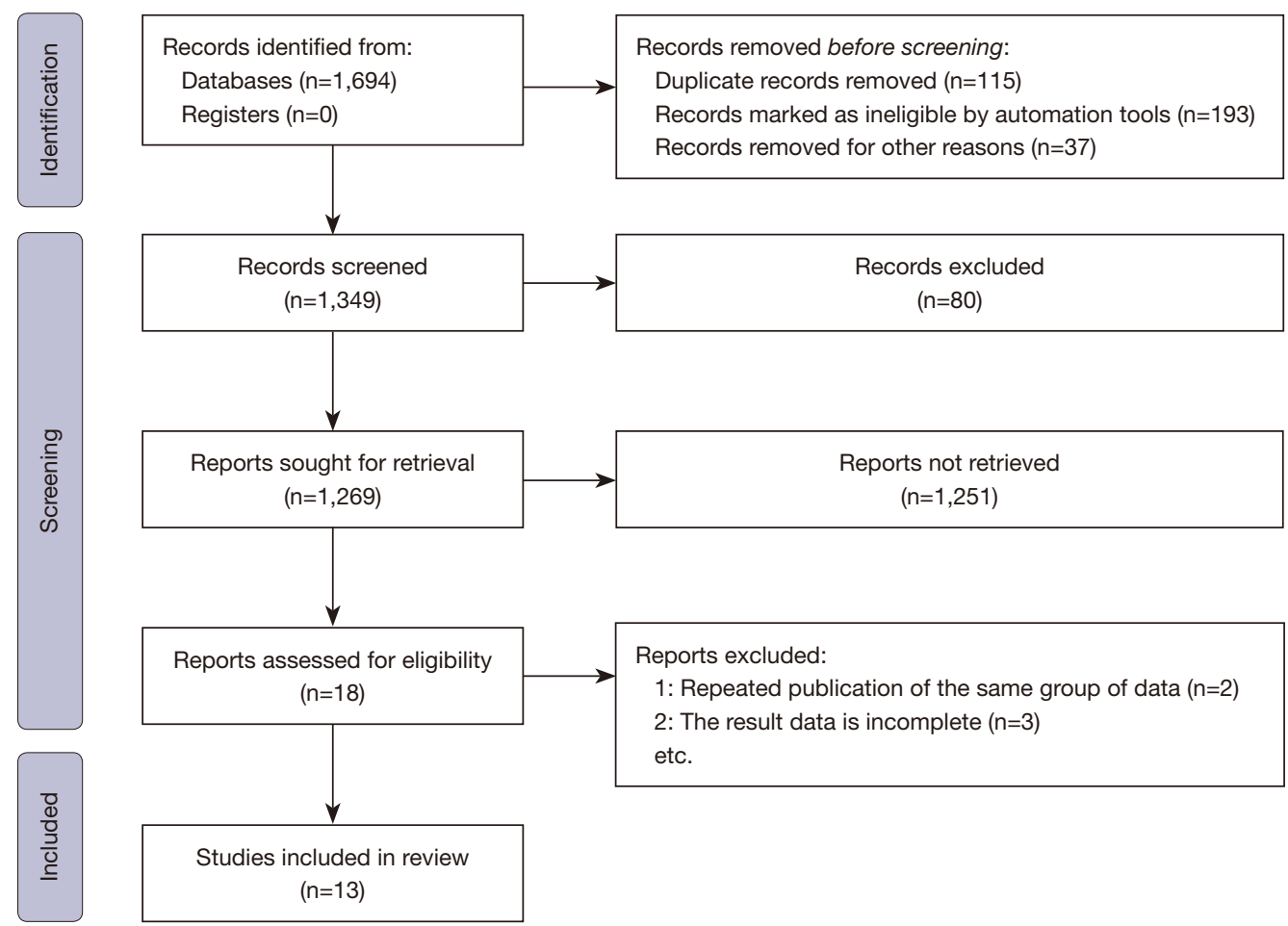

Figure 1 Literature retrieval process.

Handbook 5.0.2 software, and Review Manager 5.3 software (Cochrane collaboration network) were adopted to merge the statistics of the included articles, evaluate risk of bias of the included articles, and perform meta-analysis of the combined statistics. Forest diagrams and funnel diagrams were then drawn on the basis of the analysis results. For meta-analysis, the articles were examined for heterogeneity using the $\mathrm{I}^{2}$ test to observe whether the studies could be combined, and the $\mathrm{P}$ value was undertaken as an index to evaluate the heterogeneity. When $\mathrm{I}^{2}<50 \%$ and $\mathrm{P}>0.05$, there was no statistical heterogeneity among the trials, and the fixed effects model was selected for meta-analysis. However, when $\mathrm{I}^{2} \geq 50 \%$ and $\mathrm{P} \leq 0.05$, statistical heterogeneity was considered to exist among the trials, and the random effects model was selected for meta-analysis. The combined effect size of the two groups of evaluation index data was the odds ratio (OR) value and its $95 \% \mathrm{CI}$, and the forest map was drawn according to the integrated system evaluation results to display the research conclusions. Results with high heterogeneity were analyzed with the method of elimination by article to explore the possible sources of heterogeneity, and sensitivity analysis was performed on the results.

\section{Results}

\section{Literature search results}

A total of 1,694 relevant literatures were retrieved in this study, of which 1,086 were retrieved from the PubMed database, 305 from Embase, and 303 from Medline. After reading the titles and abstracts, 1,251 articles that clearly did not meet the inclusion criteria were excluded. After reading the full texts, 80 studies were excluded, and 13 articles (24-36) that met the inclusion criteria were finally included. A total of 993 patients were enrolled on chemotherapeutic therapy and 928 on placebo (Figure 1, Table 1).

\section{Bias-risk assessment of included articles}

The Cochrane Handbook (version 5.0.2) systematic review writing manual was used to evaluate the risk of bias in the 13 included articles. Review Manager 5.3 was employed to output the risk of bias chart (Figures 2,3).

The Jadad scale was used to evaluate the quality of each included study. We found that all 13 included articles had a low risk of bias, which meets the requirements of 
Table 1 Basic characteristics of the included literature

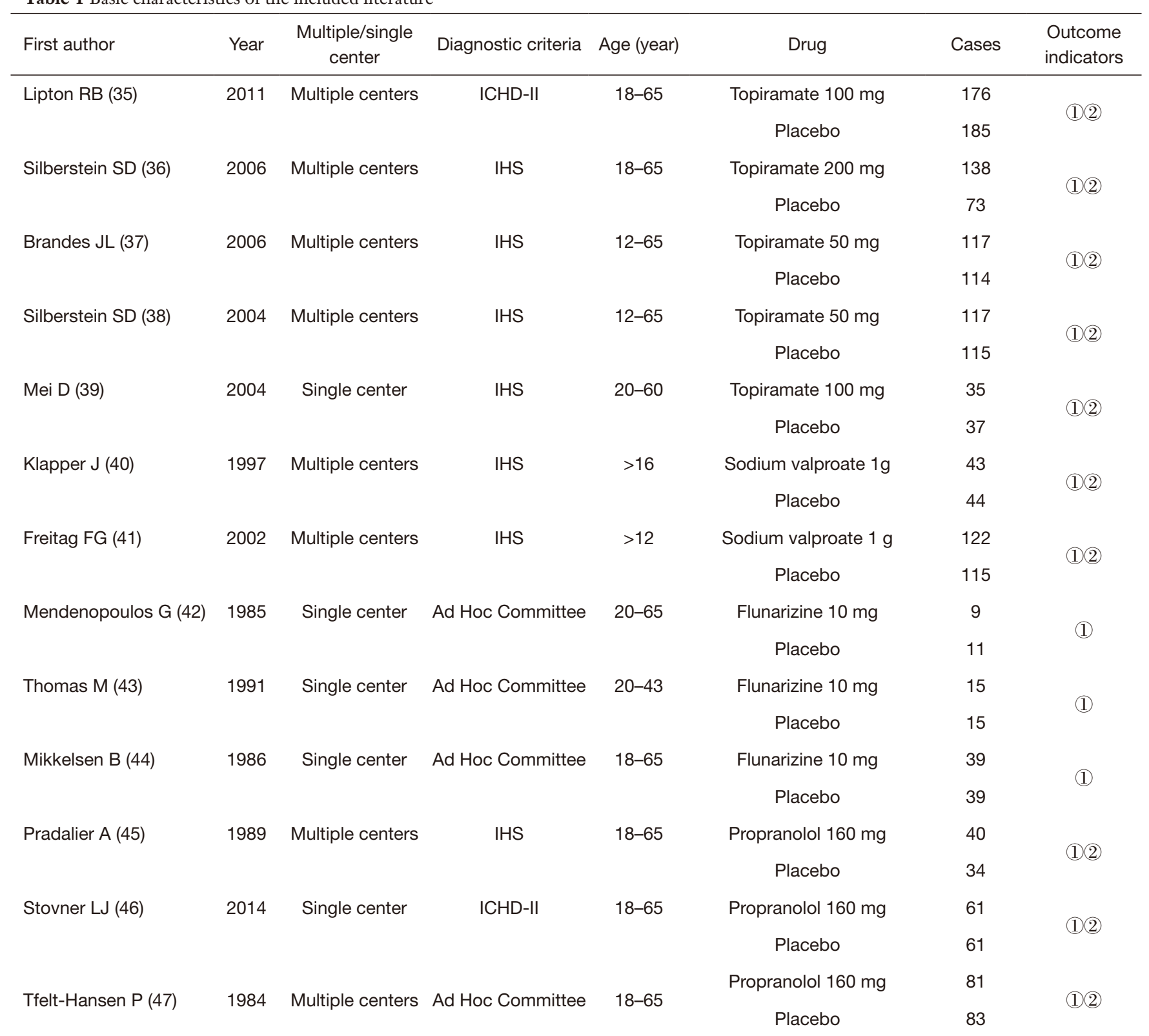

(1) : any adverse events; (2) : frequency of headache. ICHD-II, the International Classification of Headache Disorders 2nd Edition; IHS, International Headache Society Classification; Ad Hoc Committee, Ad Hoc Committee on Classification of Headache.

subsequent analysis (Table 2).

\section{Mate-analysis of incidence of adverse events during chemotherapeutic therapy}

A total of 13 studies were included in the meta-analysis, which first compared the differences in the incidence of adverse events after treatment with different chemicals and placebo. The results of heterogeneity analysis showed that $\mathrm{I}^{2}=86 \%, \mathrm{P}<0.00001$, so the random-effect model was used for meta-analysis. The comprehensive effect model showed that risk difference $(\mathrm{RD})=0.11,95 \% \mathrm{CI}: 0.03$ to $0.20, \mathrm{Z}=2.70, \mathrm{P}=0.007$. The results showed that there was statistically significant difference in the probability of adverse events between patients treated with chemical drugs and placebo $(\mathrm{P}<0.05$; Figure 4$)$. 


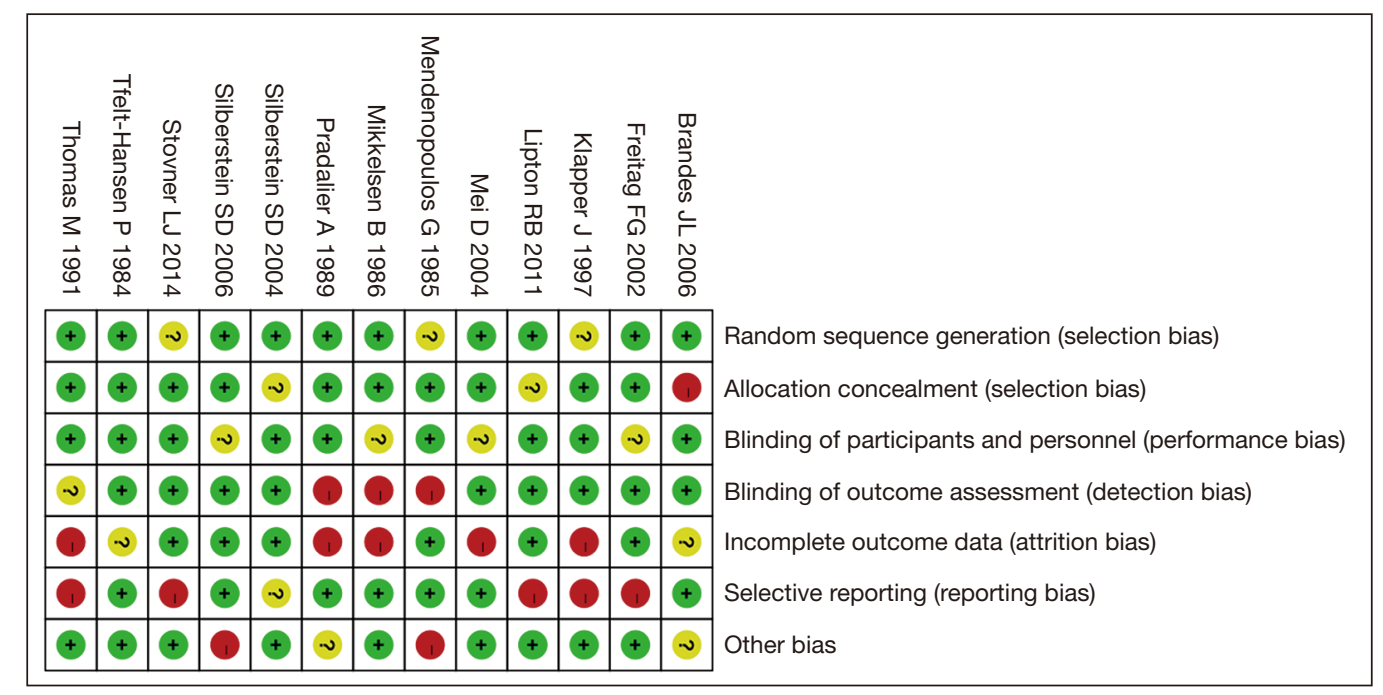

Figure 2 The bias-risk assessment diagram of the included articles.

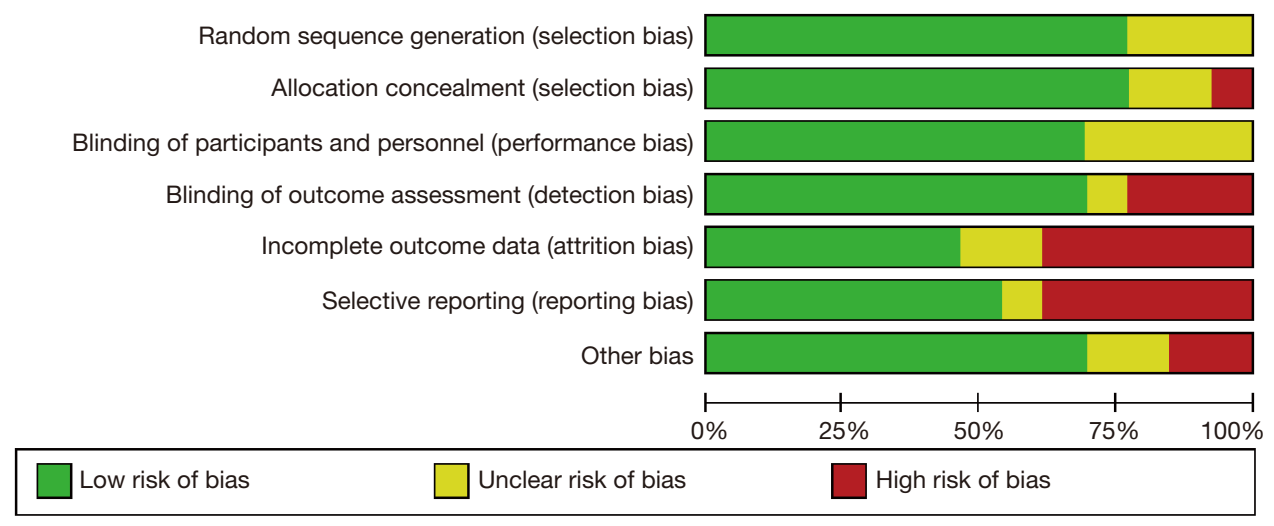

Figure 3 The bias evaluation bar graph of the included articles.

An inverted funnel plot was drawn to detect the publication bias of the included literatures. The results showed that almost all literatures fell into the plot, and only 6 literatures deviated. However, the inverted funnel plot had good symmetry overall, indicating that there was no obvious publication bias in the included literature (Figure 5).

\section{Meta-analysis of frequency of headache after chemotherapy}

A total of 10 studies were included in the meta-analysis, which compared the differences in the frequency of headache after treatment with different chemicals and placebo. The results of heterogeneity analysis showed that
$\mathrm{I}^{2}=92 \%, \mathrm{P}<0.00001$, so the random-effect model was used for meta-analysis. The results of comprehensive effect model showed that mean difference $(\mathrm{MD})=-1.31,95 \% \mathrm{CI}$ : -1.89 to $-0.73, Z=4.40, P<0.0001$. The results showed that there was statistically significant difference in the frequency of headache after chemotherapy and placebo treatment $(\mathrm{P}<0.05$; Figure 6).

An inverted funnel plot was drawn to detect the publication bias of the included literatures. The results showed that almost all literatures fell into the plot, and only 3 literatures deviated. However, the inverted funnel plot had good symmetry overall, indicating that there was no obvious publication bias in the included literature (Figure 7). 
Table 2 Basic characteristics of the included literature

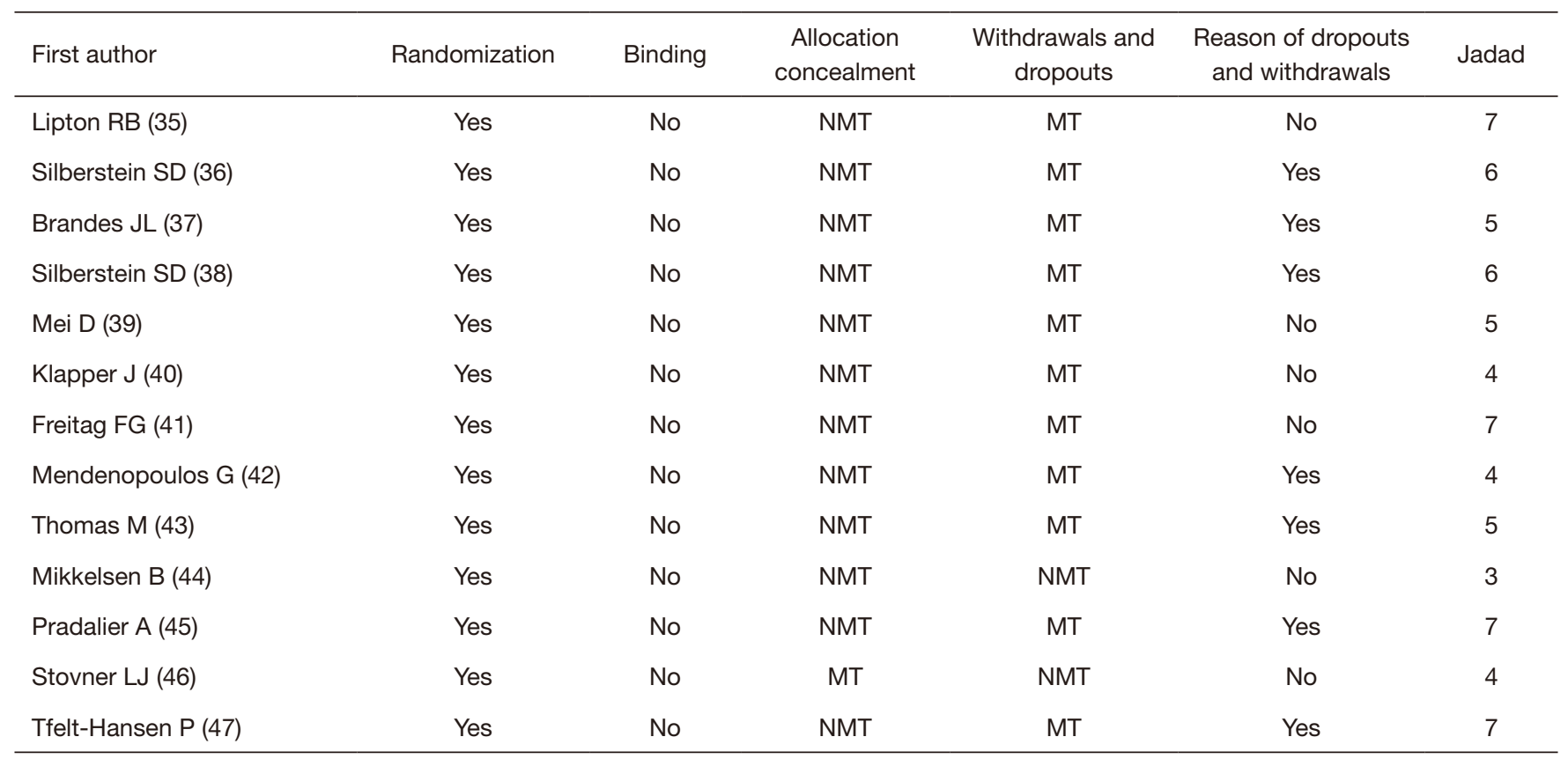

MT, mentioned; NMT, not mentioned.

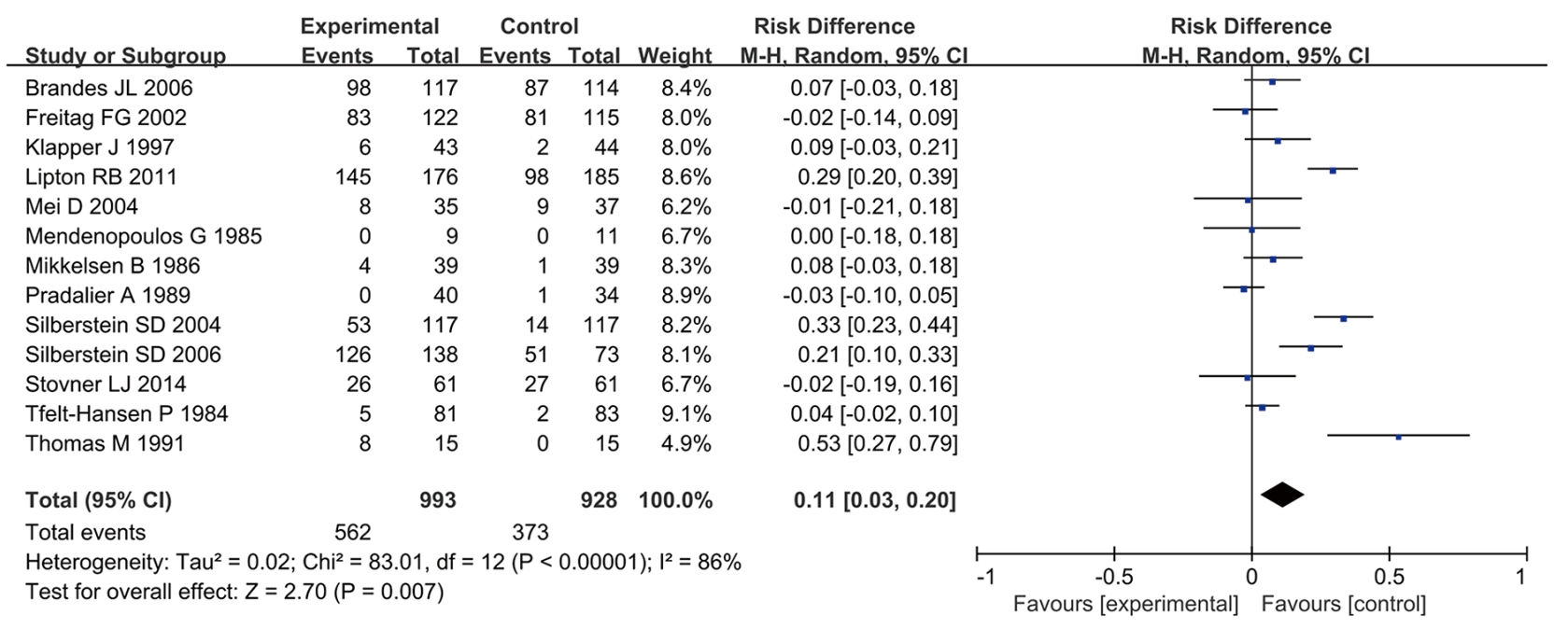

Figure 4 Forest plot of the incidence of adverse events after chemotherapy for migraine. CI, confidence interval.

\section{Meta-analysis of evaluation of therapeutic effect of different chemical drugs}

Evaluation of therapeutic effect of topiramate

A total of 5 studies were included in the meta-analysis, which compared the difference in the incidence of adverse events after topiramate and placebo treatment. The results of heterogeneity analysis showed that $\mathrm{I}^{2}=85 \%$ and $\mathrm{P}<0.0001$, so the random-effect model was used for meta-analysis. The results of the comprehensive effect model showed that OR $=3.63,95 \%$ CI: 1.65 to $7.97, \mathrm{Z}=3.21, \mathrm{P}=0.001$. The results showed that there was statistically significant difference in the incidence of adverse events between topiramate and placebo $(\mathrm{P}<0.05)$. The result was shown in Figure 8.

Secondly, the difference of headache frequency between 
the two kinds of drugs was compared. The results of heterogeneity analysis showed that $\mathrm{I}^{2}=80 \%$ and $\mathrm{P}=0.0005$, so the random effect model was used for meta-analysis. The results of comprehensive effect model showed that $\mathrm{MD}=-1.31,95 \% \mathrm{CI}:-1.87$ to $-0.75, \mathrm{Z}=4.59, \mathrm{P}<0.00001$. The results showed that there was statistically significant difference in the frequency of headache between topiramate and placebo $(\mathrm{P}<0.05$; Figure 9).

The inverted funnel plot was drawn to detect the publication bias of the included literatures, and the results showed that the inverted funnel plot had good symmetry, and the included literatures were almost distributed on both sides of the midline. This indicated that the included literature had low publication bias (Figure 10).

\section{Evaluation of therapeutic effect of sodium valproate}

A total of 5 studies were included in the meta-analysis, which compared the difference in the incidence of adverse

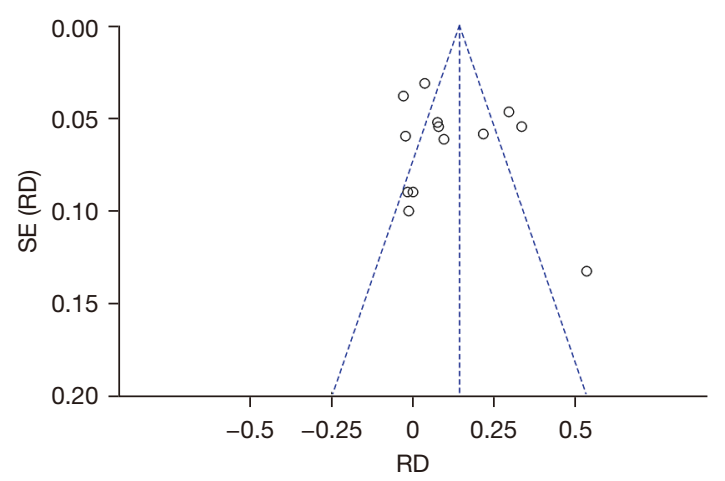

Figure 5 Inverted funnel plot of adverse events after chemotherapy for migraine. SE, standard error; RD, rate difference. events after valproate and placebo treatment. The results of heterogeneity analysis showed that $\mathrm{I}^{2}=75 \%, \mathrm{P}=0.003$, so the random effect model was used for meta-analysis. Comprehensive effect model test results showed that RD $=0.10,95 \%$ CI: -0.02 to $0.23, Z=1.59, P=0.11$. There was no significant difference in the incidence of adverse events between patients treated with sodium valproate and placebo $(\mathrm{P}>0.05$; Figure 11).

Secondly, the difference in the frequency of headache after the two types of drug treatment was compared, and a total of 2 literatures were included in the analysis. The results of heterogeneity analysis showed that $\mathrm{I}^{2}=69 \%$, $\mathrm{P}=0.07$, so the random effect model was used for metaanalysis. The results of comprehensive effect model showed that $\mathrm{MD}=-0.92,95 \% \mathrm{CI}:-1.80$ to $-0.04, \mathrm{Z}=2.05, \mathrm{P}=0.04$. The frequency of headache between patients treated with sodium valproate and placebo was statistically significant $(\mathrm{P}<0.05$; Figure 12).

The inverted funnel plot was drawn to detect the publication bias of the included literatures. The results showed that the inverted funnel plot had good symmetry, the included literatures were almost distributed on both sides of the midline, and only a few literatures did not fall into the plot. This indicated that the included literature had low publication bias (Figure 13).

\section{Evaluation of therapeutic effect of flunarizine}

A total of 3 studies were included in the meta-analysis to compare the difference in the incidence of adverse events after flunarizine and placebo treatment. The results of heterogeneity analysis showed that $\mathrm{I}^{2}=44 \%, \mathrm{P}=0.17$, so the fixed-effect model was used for meta-analysis. The results of comprehensive effect model showed that OR $=1.17,95 \%$

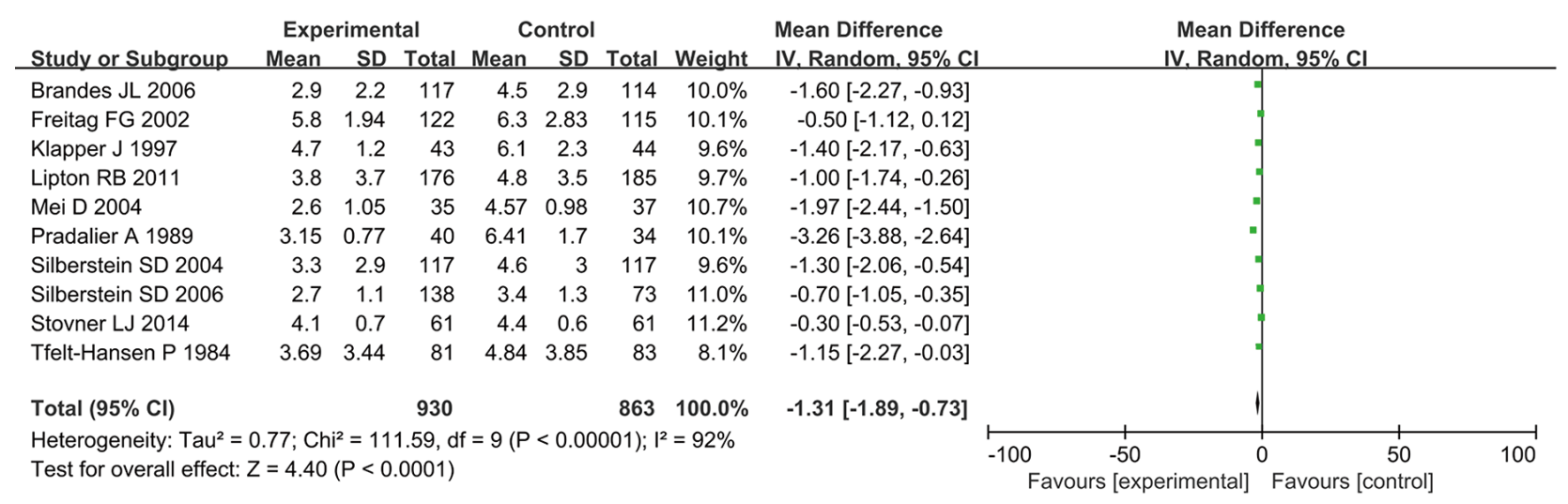

Figure 6 Forest plot of the frequency of headache after chemotherapy for migraine. CI, confidence interval. 
CI: 0.62 to $2.21, \mathrm{Z}=0.47, \mathrm{P}=0.64$. There was no significant difference in the incidence of adverse events between flunarizine and placebo $(\mathrm{P}>0.05$; Figure 14$)$.

Secondly, the difference of headache frequency between the two kinds of drugs was compared. The results of heterogeneity analysis showed that $\mathrm{I}^{2}=97 \%, \mathrm{P}<0.00001$, so the random-effect model was used for meta-analysis. The

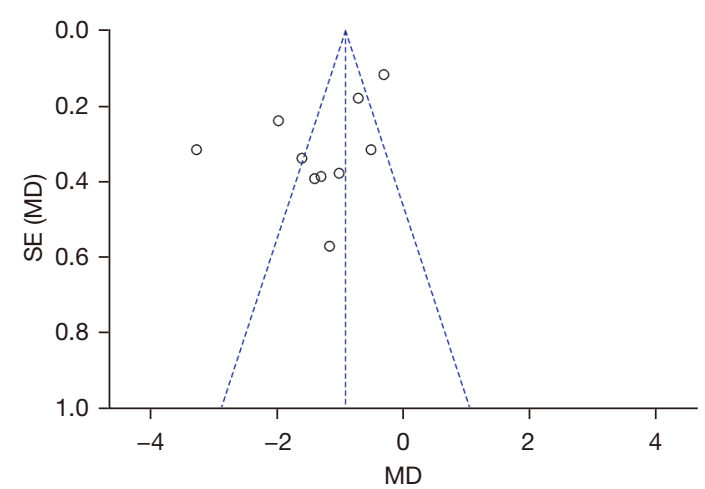

Figure 7 Inverted funnel plot of headache frequency after chemotherapy for migraine. SE, standard error; MD, mean difference. results of comprehensive effect model showed that $\mathrm{MD}$ $=-1.57,95 \% \mathrm{CI}:-3.67$ to $0.53, \mathrm{Z}=1.46, \mathrm{P}=0.14$. There was no significant difference in the frequency of headache between flunarizine and placebo $(\mathrm{P}>0.05$; Figure 15).

The inverted funnel plot was drawn to detect the publication bias of the included literatures. The results showed that the inverted funnel plot had good symmetry, the included literatures were almost distributed on both sides of the midline, and only a few literatures did not fall into the plot. This indicated that the included literature had low publication bias (Figure 16).

\section{Discussion}

Migraine is a clinically common neurovascular disease, which is triggered by the dysfunction of 5-hydroxytryptamine (5-HT) neurons in the brain, and some migraine patients may be converted to chronic migraine. Although the pathogenesis of migraine remains unclear, there are currently two theories: the conical spreading depression (CSD) theory (48) and the trigeminal vascular reflex theory (49), which can comprehensively reflect the progression of migraine from acute to chronic

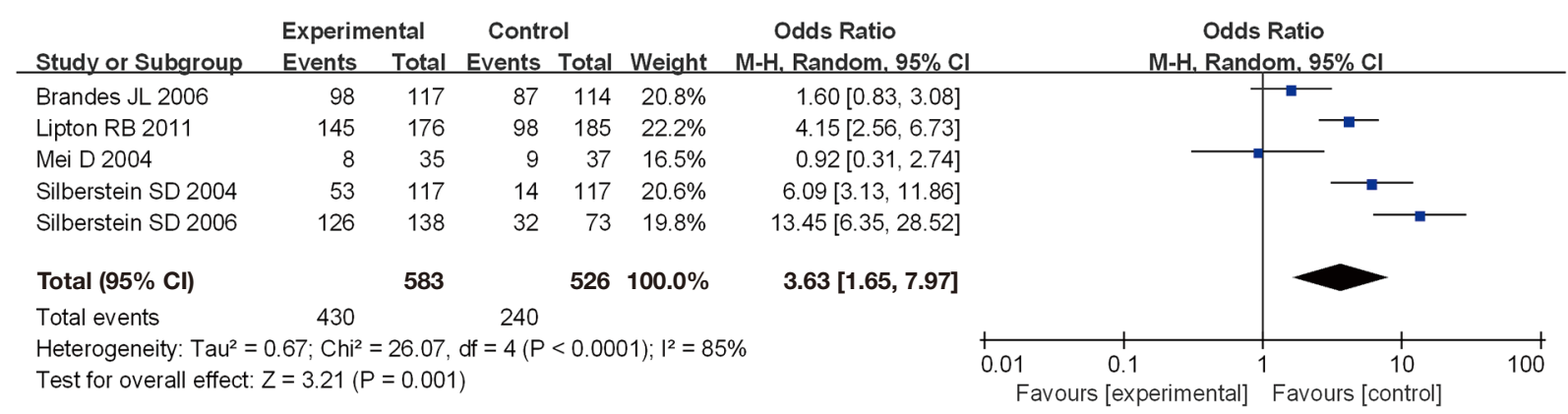

Figure 8 Forest plot of adverse event rates after topiramate treatment for migraine. CI, confidence interval.

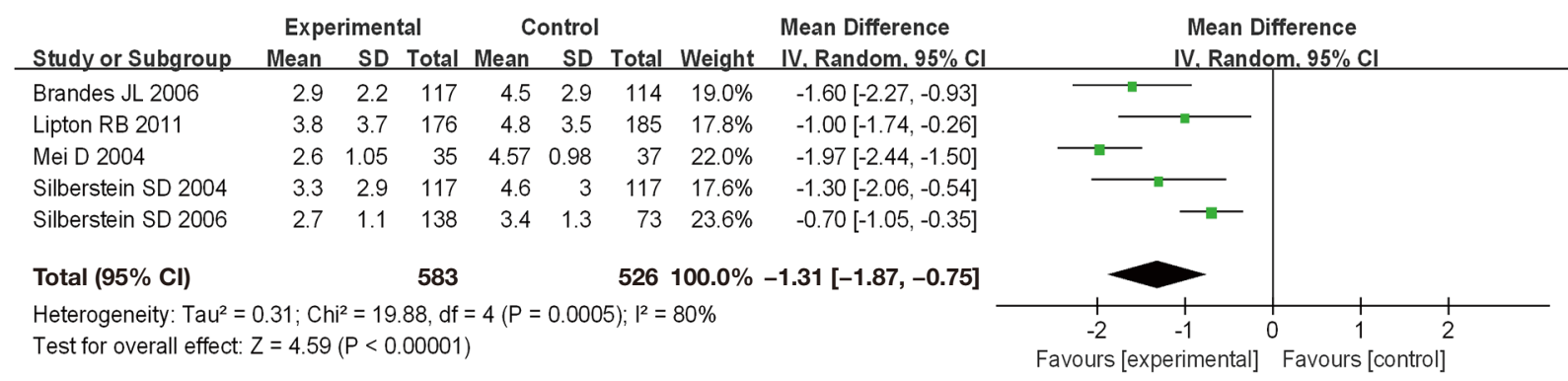

Figure 9 Forest plot of headache frequency after topiramate treatment for migraine. CI, confidence interval. 

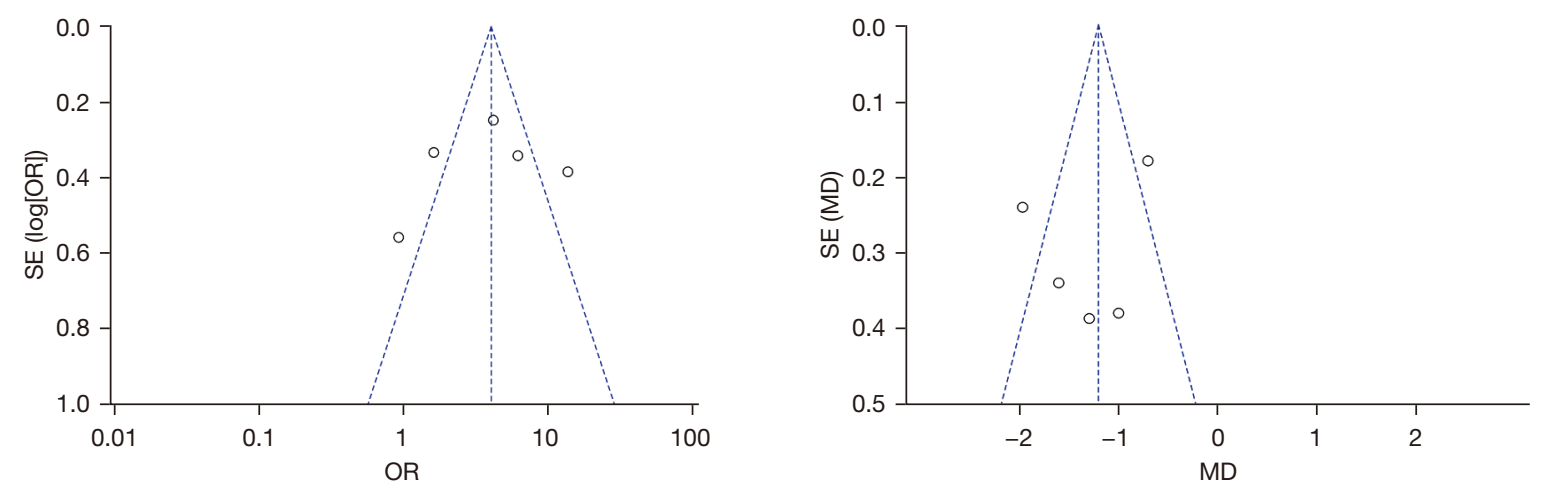

Figure 10 Inverted funnel plot of topiramate after treatment of migraine. SE, standard error; OR, odds ratio; MD, mean difference.

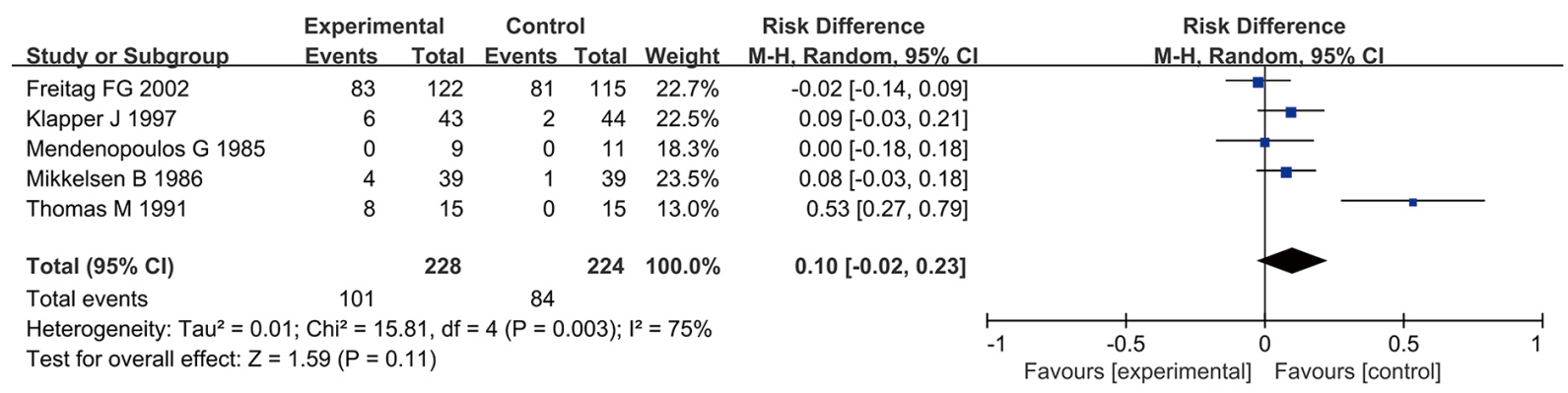

Figure 11 Forest plot of adverse event rates after sodium valproate therapy for migraine. CI, confidence interval.

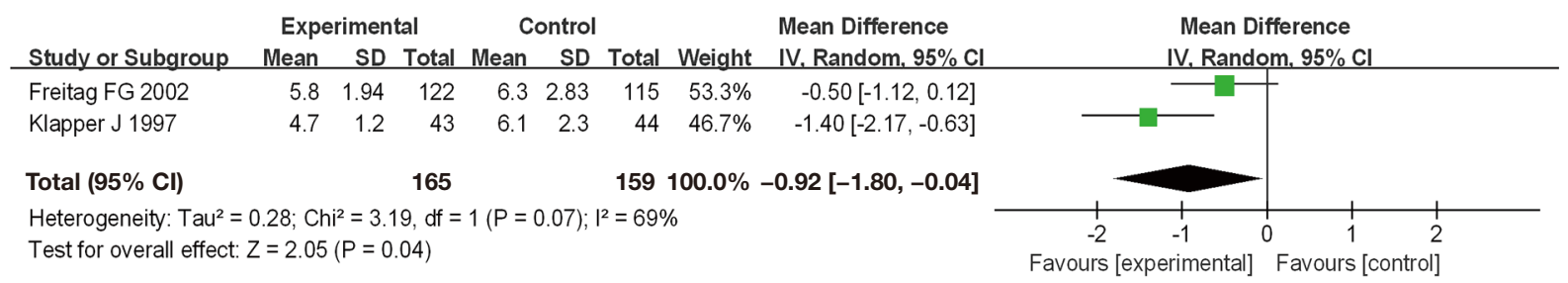

Figure 12 Forest plot of headache frequency after sodium valproate treatment of migraine. CI, confidence interval.

onset. Topiramate increases gamma-aminobutyric acid activity and activates its receptor, resulting in increased chloride influx and significantly increased inhibitory neurotransmitter activity, thus preventing migraine attacks (50). Sodium valproate can enhance the activity of glutamate carboxylase (GAD), a key enzyme in the synthesis of gamma-aminobutyric acid, thereby increasing the level of gamma-aminobutyric acid, and ultimately producing a neuroprotective effect through the regulation of inhibitory neurotransmitter levels to prevent migraine (51).

According to the results of the meta-analysis included in the literature, prophylactic treatment of migraine with chemical agents was more difficult to tolerate than placebo. However, of the three chemicals included in the analysis, topiramate was the least well tolerated, with a higher incidence of adverse events after treatment than in the placebo group. The results also showed that topiramate significantly reduced drug compliance when used to prevent migraine. The incidence of adverse events after sodium valproate treatment was similar to that of placebo, and the frequency of headache was significantly reduced after treatment. These results suggest that valproate can be used 

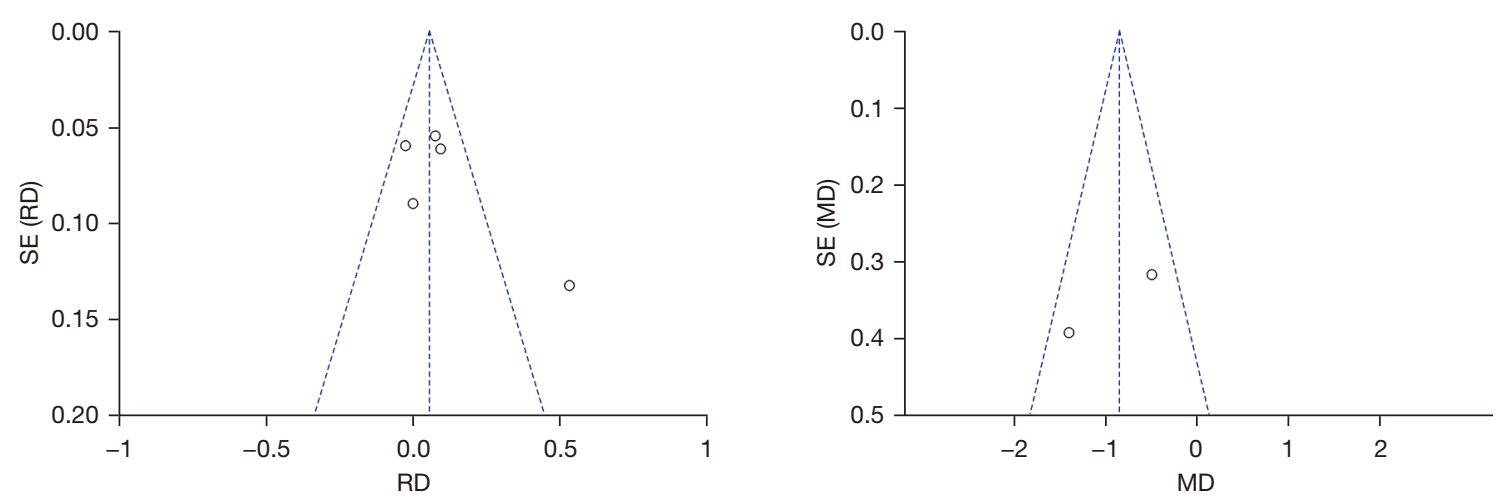

Figure 13 Inverted funnel plot of the effect of sodium valproate on migraine. SE, standard error; RD, rate difference; MD, mean difference.

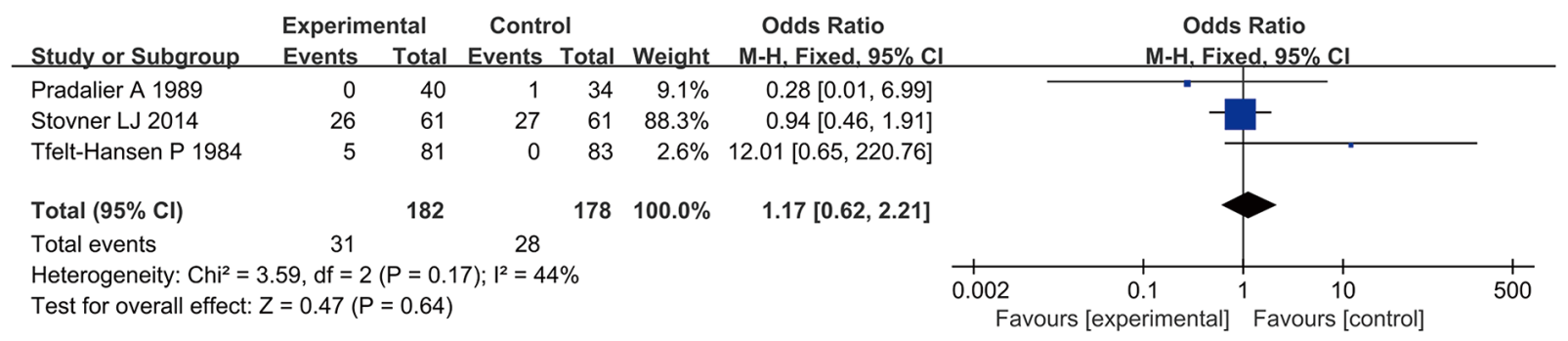

Figure 14 Forest plot of adverse event rates after flunarizine treatment with migraine. CI, confidence interval.

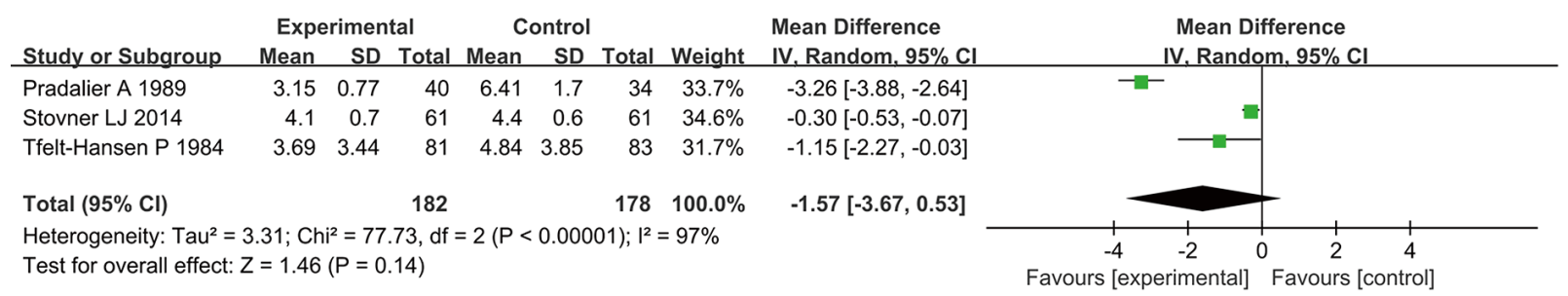

Figure 15 Forest plot of headache frequency after flunarizine treatment for migraine. CI, confidence interval.

in most migraine patients with low incidence of adverse events, but it is recommended that patients who can't tolerate the timely adjustment of medication. There were no significant differences in the incidence of adverse events and frequency of headache between flunarizine and placebo group, which may be due to the small number of literatures and small sample size included in the analysis, which may have large deviations, leading to a slightly poor reliability of the results. Therefore, the tolerance of flunarizine needs to be further verified.

In summary, this study showed that for migraine prevention, valproate and propranolol had better tolerability, which provides a basis for clinical treatment. However, more large sample clinical trials should be conducted for the prevention and treatment of migraine. In the future, we will conduct many clinical trials to further verify the results of this study. Also, more systems network meta-analyses should be performed to further evaluate the drug tolerance of migraine prevention.

\section{Conclusions}

To investigate the tolerance of chemical drugs, this paper carried out Mate analysis on the tolerance and therapeutic 

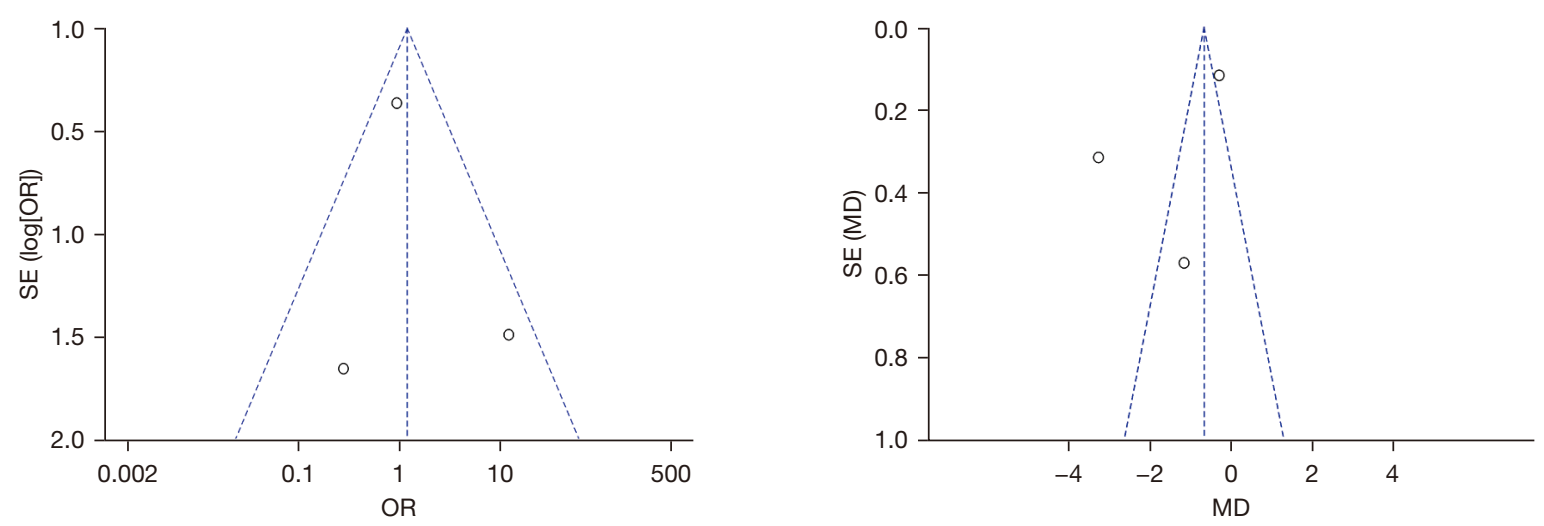

Figure 16 Inverted funnel plot of flunarizine after treatment of migraine. SE, standard error; OR, odds ratio; MD, mean difference.

effect of topiramate, sodium valproate, flunarizine, and propranolol in the treatment of migraine. A total of 13 literatures were included in this paper, and it was found that patients had good tolerance when sodium valproate and propranolol were used to treat migraine.

\section{Acknowledgments}

Funding: None.

\section{Footnote}

Reporting Checklist: The authors have completed the PRISMA reporting checklist. Available at https://apm. amegroups.com/article/view/10.21037/apm-21-3719/rc

Conflicts of Interest: All authors have completed the ICMJE uniform disclosure form (available at https://apm. amegroups.com/article/view/10.21037/apm-21-3719/coif). The authors have no conflicts of interest to declare.

Ethical Statement: The authors are accountable for all aspects of the work in ensuring that questions related to the accuracy or integrity of any part of the work are appropriately investigated and resolved.

Open Access Statement: This is an Open Access article distributed in accordance with the Creative Commons Attribution-NonCommercial-NoDerivs 4.0 International License (CC BY-NC-ND 4.0), which permits the noncommercial replication and distribution of the article with the strict proviso that no changes or edits are made and the original work is properly cited (including links to both the formal publication through the relevant DOI and the license). See: https://creativecommons.org/licenses/by-nc-nd/4.0/.

\section{References}

1. Yu S, Liu R, Zhao G, et al. The prevalence and burden of primary headaches in China: a population-based door-todoor survey. Headache 2012;52:582-91.

2. Rees DI, Sabia JJ. Migraine headache and labor market outcomes. Health Econ 2015;24:659-71.

3. Lanteri-Minet M. Economic burden and costs of chronic migraine. Curr Pain Headache Rep 2014;18:385.

4. Su M, Yu S. Chronic migraine: A process of dysmodulation and sensitization. Mol Pain 2018;14:1744806918767697.

5. Schwedt TJ. Chronic migraine. BMJ 2014;348:g1416.

6. Lipton RB, Silberstein SD. Episodic and chronic migraine headache: breaking down barriers to optimal treatment and prevention. Headache 2015;55 Suppl 2:103-22; quiz 123-6.

7. Rothner AD. Migraine Variants in Children. Pediatr Ann 2018;47:e50-4.

8. Dieterich M, Obermann M, Celebisoy N. Vestibular migraine: the most frequent entity of episodic vertigo. J Neurol 2016;263 Suppl 1:S82-9.

9. McDermott MJ, Tull MT, Gratz KL, et al. Comorbidity of migraine and psychiatric disorders among substancedependent inpatients. Headache 2014;54:290-302.

10. Colombo B, Teggi R; NIVE Project. Vestibular migraine: who is the patient? Neurol Sci 2017;38:107-10.

11. Peters GL. Migraine overview and summary of current and emerging treatment options. Am J Manag Care 2019;25:S23-34.

12. Nye BL, Thadani VM. Migraine and epilepsy: review of the literature. Headache 2015;55:359-80. 
13. Silberstein SD. Preventive Migraine Treatment. Continuum (Minneap Minn) 2015;21:973-89.

14. Gazerani P, Cairns BE. Dysautonomia in the pathogenesis of migraine. Expert Rev Neurother 2018;18:153-65.

15. Aurora SK, Brin MF. Chronic Migraine: An Update on Physiology, Imaging, and the Mechanism of Action of Two Available Pharmacologic Therapies. Headache 2017;57:109-25.

16. Charles A. The pathophysiology of migraine: implications for clinical management. Lancet Neurol 2018;17:174-82.

17. Ashina M. Migraine. N Engl J Med 2020;383:1866-76.

18. Andreou AP, Edvinsson L. Mechanisms of migraine as a chronic evolutive condition. J Headache Pain 2019;20:117.

19. Dodick DW. Migraine. Lancet 2018;391:1315-30.

20. Xu H, Han W, Wang J, et al. Network meta-analysis of migraine disorder treatment by NSAIDs and triptans. J Headache Pain 2016;17:113.

21. Mayans L, Walling A. Acute Migraine Headache: Treatment Strategies. Am Fam Physician 2018;97:243-51.

22. Ong JJY, De Felice M. Migraine Treatment: Current Acute Medications and Their Potential Mechanisms of Action. Neurotherapeutics 2018;15:274-90.

23. Bostani A, Rajabi A, Moradian N, et al. The effects of cinnarizine versus sodium valproate in migraine prophylaxis. Int J Neurosci 2013;123:487-93.

24. Becker WJ. The Diagnosis and Management of Chronic Migraine in Primary Care. Headache 2017;57:1471-81.

25. Chronicle EP, Mulleners WM. WITHDRAWN: Anticonvulsant drugs for migraine prophylaxis. Cochrane Database Syst Rev 2016;(5):CD003226.

26. Chiang CC, Schwedt TJ. Calcitonin gene-related peptide (CGRP)-targeted therapies as preventive and acute treatments for migraine-The monoclonal antibodies and gepants. Prog Brain Res 2020;255:143-70.

27. Yang Y, Ligthart L, Terwindt GM, et al. Genetic epidemiology of migraine and depression. Cephalalgia 2016;36:679-91.

28. Medrea I, Christi S. Chronic Migraine - Evolution of the Concept and Clinical Implications. Headache 2018;58:1495-500.

29. Liang J, Liu X, Pan M, et al. Blockade of Nav1.8 currents in nociceptive trigeminal neurons contributes to antitrigeminovascular nociceptive effect of amitriptyline. Neuromolecular Med 2014;16:308-21.

30. Saito H, Katagiri A, Okada S, et al. Ascending projections of nociceptive neurons from trigeminal subnucleus caudalis: A population approach. Exp Neurol 2017;293:124-36.
31. Dodick DW, Freitag F, Banks J, et al. Topiramate versus amitriptyline in migraine prevention: a 26-week, multicenter, randomized, double-blind, double-dummy, parallel-group noninferiority trial in adult migraineurs. Clin Ther 2009;31:542-59.

32. Minen MT, Begasse De Dhaem O, Kroon Van Diest A, et al. Migraine and its psychiatric comorbidities. J Neurol Neurosurg Psychiatry 2016;87:741-9.

33. Lenox-Smith AJ, Jiang Q. Venlafaxine extended release versus citalopram in patients with depression unresponsive to a selective serotonin reuptake inhibitor. Int Clin Psychopharmacol 2008;23:113-9.

34. Ozyalcin SN, Talu GK, Kiziltan E, et al. The efficacy and safety of venlafaxine in the prophylaxis of migraine. Headache 2005;45:144-52.

35. Lipton RB, Silberstein S, Dodick D, et al. Topiramate intervention to prevent transformation of episodic migraine: the topiramate INTREPID study. Cephalalgia 2011;31:18-30.

36. Silberstein SD, Hulihan J, Karim MR, et al. Efficacy and tolerability of topiramate $200 \mathrm{mg} / \mathrm{d}$ in the prevention of migraine with/without aura in adults: a randomized, placebo-controlled, double-blind, 12-week pilot study. Clin Ther 2006;28:1002-11.

37. Brandes JL, Kudrow DB, Rothrock JF, et al. Assessing the ability of topiramate to improve the daily activities of patients with migraine. Mayo Clin Proc 2006;81:1311-9.

38. Silberstein SD, Neto W, Schmitt J, et al. Topiramate in migraine prevention: results of a large controlled trial. Arch Neurol 2004;61:490-5.

39. Mei D, Capuano A, Vollono C, et al. Topiramate in migraine prophylaxis: a randomised double-blind versus placebo study. Neurol Sci 2004;25:245-50.

40. Klapper J. Divalproex sodium in migraine prophylaxis: a dose-controlled study. Cephalalgia 1997;17:103-8.

41. Freitag FG, Collins SD, Carlson HA, et al. A randomized trial of divalproex sodium extended-release tablets in migraine prophylaxis. Neurology 2002;58:1652-9.

42. Mendenopoulos G, Manafi T, Logothetis I, et al. Flunarizine in the prevention of classical migraine: a placebo-controlled evaluation. Cephalalgia 1985;5:31-7.

43. Thomas M, Behari M, Ahuja GK. Flunarizine in migraine prophylaxis: an Indian trial. Headache 1991;31:613-5.

44. Mikkelsen B, Pedersen KK, Christiansen LV. Prophylactic treatment of migraine with tolfenamic acid, propranolol and placebo. Acta Neurol Scand 1986;73:423-7.

45. Pradalier A, Serratrice G, Collard M, et al. Long-acting propranolol in migraine prophylaxis: results of a double- 
blind, placebo-controlled study. Cephalalgia 1989;9:247-53.

46. Stovner LJ, Linde M, Gravdahl GB, et al. A comparative study of candesartan versus propranolol for migraine prophylaxis: A randomised, triple-blind, placebocontrolled, double cross-over study. Cephalalgia 2014;34:523-32.

47. Tfelt-Hansen P, Standnes B, Kangasneimi P, et al. Timolol vs propranolol vs placebo in common migraine prophylaxis: a double-blind multicenter trial. Acta Neurol Scand 1984;69:1-8.

Cite this article as: Zhang Y, Deng Y, Zhang S, Du X, Ji Y. Systematic review and meta-analysis of a variety of chemicals to treat migraine in the neurology department. Ann Palliat Med 2022;11(1):98-112. doi: 10.21037/apm-21-3719
48. Kahriman A, Zhu S. Migraine and Tension-Type Headache. Semin Neurol 2018;38:608-18.

49. Chou TM, Chen SP. Animal Models of Chronic Migraine. Curr Pain Headache Rep 2018;22:44.

50. Ha H, Gonzalez A. Migraine Headache Prophylaxis. Am Fam Physician 2019;99:17-24.

51. Marmura MJ. Triggers, Protectors, and Predictors in Episodic Migraine. Curr Pain Headache Rep 2018;22:81.

(English Language Editor: A. Kassem) 